Jurnal Media Pertanian Vol. 1 No. 1 Tahun 2016 Hal. 36 - 44

Media Komunikasi Hasil Penelitian dan Review Literatur Bidang Ilmu Agronomi ISSN $2503-1279$

\title{
UJI EFEKTIFITAS PENGENDALIAN GULMA SECARA KIMIAWI dan MANUAL pada LAHAN REPLANTING KARET (Hevea brasiliensis Muell.Arg.) di DUSUN SUKA DAMAI DESA PONDOK MEJA KABUPATEN MUARO JAMBI
}

\author{
Hayata $^{1 *}$, Araz Meilin ${ }^{1}$ dan Tari Rahayu ${ }^{2}$ \\ ${ }^{1}$ Program Studi Agroteknologi, Fakultas Pertanian Universitas Batanghari \\ Jl. Slamet Riyadi-Broni, Jambi 36122 Telp. +62074160103 \\ ${ }^{2}$ Alumni Program Studi Agroteknologi, Fakultas Pertanian Universitas Batanghari \\ *email korespondensi ; atahayata@yahoo.com
}

\begin{abstract}
The purpose of this research was to know: 1) weed dominancy in rubber replanting plantations before controlling, 2) weed control effectiveness both is chemically and manualy, 3) difference weed SDR value after the chemically and manualy. This research was conducted in comunity control have been done Plantation area eg. Suka Damai Pondok Meja village, Mestong district, Muaro Jambi Regency, Jambi province. . Research conducted for \pm 2 months ( December 2014 to January 2015). Experiment using a completely randomized design with four treatment, namely: P0: control(without treatment), P1: parakuat dichloride dose of $6 \mathrm{ml} 2400 \mathrm{ml}^{-1}$ water for treatment plots, P2: glyphosate isopropyl amine dose of $6 \mathrm{ml} 2400 \mathrm{ml}$ water ${ }^{-1}$ for treatment plots, P3: manualy control by pulling. Each treatment has four times replication. Dominant weed acreage replanting of rubber Suka damai before treatment weed control is Euphorbia hirta (SDR 29.02\%), Cleome rutidospermae (SDR $19.70 \%$ ), Paspalum conjugatum (SDR 12.82\%), Cyperus pilosus (SDR 7.99\%), and Clidemia hirta (SDR 6.49\%). Chemically weed control treatment with the herbicide paraquat and glyphosate herbicides are more effective in suppressing the growth of new weed than manually treatment. There is a difference SDR value after being given by chemically and manually weeds controling treatment the most dominant weed, Euphorbia hirta has increased from $29.02 \%$ to $45.80 \%$, Cleome rutidospermae weed has decreased the SDR value from $19.70 \%$ to $15.26 \%$.
\end{abstract}

Keywords : herbicides, dominant weeds, rubber tree, SDR

\begin{abstract}
Abstrak
Penelitian ini bertujuan untuk mengetahui : 1) dominansi gulma di perkebunan replanting karet sebelum pengendalian, 2) efektifitas pengendalian gulma secara kimiawi dan manual, 3) perbedaan nilai SDR gulma yang tumbuh setelah dilakukan pengendalian secara kimiawi dan manual. Penelitian dilakukan di areal perkebunan rakyat replanting berumur 3 tahun dusun Suka damai desa Pondok Meja, kecamatan Mestong, kabupaten Muaro Jambi, provinsi Jambi.. Penelitian dilakukan selama \pm 2 bulan mulai bulan Desember 2014 sampai bulan Januari 2015 . Percobaan dirancang menggunakan rancangan acak lengkap satu faktor dengan empat

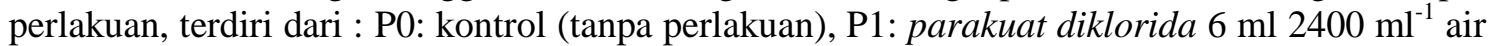
per petak perlakuan, P2: isopropyl amina glifosat $6 \mathrm{ml} 2400 \mathrm{ml}$ air ${ }^{-1}$ per petak perlakuan, P3: pengendalian manual dengan cara dicabut. Masing-masing perlakuan diulang 4 kali Gulma dominan pada areal replanting karet dusun Suka damai sebelum perlakuan pengendalian gulma adalah Euphorbia hirta (SDR 29,02\%), Cleome rutidospermae (SDR 19,70\%), Paspalum conjugatum (SDR 12,82\%), Cyperus pilosus (SDR 7,99\%), dan Clidemia hirta (SDR 6,49\%). Pengendalian gulma secara kimiawi dengan herbisida paraquat dan herbisida glifosat lebih efektif menekan pertumbuhan gulma baru dibanding pengendalian gulma secara manual.
\end{abstract}


Jurnal Media Pertanian Vol. 1 No. 1 Tahun 2016 Hal. 36 - 44

Media Komunikasi Hasil Penelitian dan Review Literatur Bidang Ilmu Agronomi

ISSN $2503-1279$

Terdapat perbedaan nilai SDR setelah perlakuan pengendalian gulma secara kimiawi dan manual pada gulma yang paling dominan, Euphorbia hirta mengalami peningkatan dari 29,02\% menjadi 45,80\%, gulma Cleome rutidospermae mengalami penurunan nilai SDR dari 19,70\% menjadi $15,26 \%$.

Kata kunci ; herbisida, gulma dominan, tanaman karet, SDR

\section{PENDAHULUAN}

Dalam pelaksanaan pembangunan perkebunan, kita dihadapkan pada kenyataan adanya hambatan utama gangguan gulma. Gulma di perkebunan karet dapat merugikan baik produksi karet itu sendiri maupun gangguan terhadap kegiatan pengelolaannya yang pada akhirnya menurunkan keuntungan usaha perkebunan tersebut (Purba, 2000).

Gulma menjadi masalah di perkebunan karet, baik di pembibitan maupun di pertanaman, pada tanaman remaja maupun yang telah menghasilkan dapat menyebabkan penurunan luas daun, jumlah daun, bobot kering, produksi bunga betina dan hasil bunga segar (Ojouderie $d k k, 1983$ dalam Anwar, 2007). Pada areal yang luas, pengendalian gulma secara manual sulit dilaksanakan karena susah mencari tenaga kerja dan waktu yang tersedia terbatas, karena itu dilakukan pengendalian dengan cara kimiawi menggunakan herbisida yang memerlukan tenaga kerja sedikit, mudah, cepat dan kebun lebih lama bersih (Anwar, 2007).

Efektifitas pemberian herbisida antara lain ditentukan oleh dosis dan waktu pemberiannya. Dosis herbisida yang tepat akan dapat mematikan gulma sasaran, tetapi jika dosis herbisida terlalu tinggi maka dapat merusak bahkan mematikan tanaman yang dibudidayakan. Pemakaian herbisida sistemik seperti glifosat memerlukan waktu untuk translokasi ke seluruh bagian gulma sehingga terjadi keracunan pada gulma (Nurjanah, 2002).

Setiap herbisida memiliki daya berantas khusus untuk golongan tertentu, herbisida dengan bahan aktif parakuat diklorida merupakan herbisida yang bersifat kontak, non selektif dengan daya kerja yang cukup cepat (Syngenta, 2002 dalam Anwar, 2007). Glifosat adalah herbisida yang bersifat sistemik, berdaya luas, non selektif untuk tanaman pertanian sehingga dianjurkan untuk pengolahan tanah dan untuk tanaman-tanaman perkebunan dengan sistem aplikasi sela (Bangun dan Pane, 1984 dalam Anwar, 2007).

Herbisida berbahan aktif parakuat diklorida mampu mengendalikan gulma berdaun lebar, sempit dan teki. Herbisida ini bersifat kontak karena mematikan gulma pada bagian yang terkena herbisida, bersifat non selektif karena mempengaruhi semua jenis tumbuhan yang terkena herbisida ini, sering digunakan untuk mengendalikan gulma yang dapat memberikan pengaruh kompetisi pada tanaman (Roesmanto, 2005 dalam Anwar, 2007).

Pengendalian gulma secara manual merupakan salah satu bagian dari pengendalian gulma secara mekanis. Pengendalian gulma secara manual tidak menggunakan alat berat, dapat dilakukan dengan cara mencabut gulma, menggunakan alat sederhana seperti parang maupun arit (Henry, 2010).

Pengendalian gulma dengan cara mencabut gulma memerlukan tenaga dan waktu yang banyak. Namun, tindakan ini menimbulkan gangguan yang minim terhadap tanaman budidaya hanya saja terkadang terjadi pengikisan atau pengurangan luas tanah karena tanah menempel pada akar-akar gulma yang dicabut. Pada percobaan-percobaan 
Jurnal Media Pertanian Vol. 1 No. 1 Tahun 2016 Hal. 36 - 44

Media Komunikasi Hasil Penelitian dan Review Literatur Bidang Ilmu Agronomi

ISSN $2503-1279$

pengendalian gulma, tindakan mencabut gulma biasanya digunakan sebagai perlakuan pembanding (Henry, 2010).

\section{METODE PENELITIAN}

Penelitian ini dilakukan di areal perkebunan rakyat dusun Suka damai desa Pondok meja, kecamatan Mestong, kabupaten Muaro Jambi, provinsi Jambi. Replanting tanaman karet berumur 3 tahun. Penelitian dilakukan selama \pm 2 bulan mulai bulan Desember 2014 sampai bulan Januari 2015.

Alat-alat yang digunakan adalah alat tulis, ember plastik, gelas ukur, kamera, map plastik, meteran, palu serta alat semprot berupa sprayer tangan. Sedangkan bahanbahan yang digunakan dalam penelitian ini adalah areal perkebunan karet replanting yang ditumbuhi gulma, kayu, paku, tali rafia, herbisida kontak dan sistemik dengan jenis: bahan aktif parakuat diklorida pada herbisida kontak dari merk dagang Noxone 297 SL, bahan aktif isopropil amina glifosat pada herbisida sistemik merk dagang Kon Up 480 SL.

Rancangan percobaan yang digunakan adalah rancangan acak lengkap satu faktor dengan empat perlakuan, terdiri dari : P0 : kontrol (tanpa perlakuan), P1 : parakuat diklorida, dosis $6 \mathrm{ml} 2400 \mathrm{ml} \mathrm{air}^{-1}$ per petak perlakuan, P2: isopropyl amina glifosat, dosis $6 \mathrm{ml} 2400 \mathrm{ml}_{\text {air }}{ }^{-1}$ per petak perlakuan, dan P3: pengendalian manual dengan cara dicabut. Masing-masing perlakuan diulang 4 kali. Penelitian dilakukan dengan membuat petak contoh $1 \mathrm{~m} \times 2 \mathrm{~m}$

Peubah yang diamati koefisien komunitas, dominansi gulma, efektifitas pengendalian kimia dan manual, dan daya tumbuh kembali.Data SDR yang diperoleh dalam analisis dominansi ditabulasi serta data perlakuan pengendalian gulma dianalisis secara deskriptif.

Nilai SDR dihitung dengan menggunakan rumus yang dikemukakan oleh Tjitrosoedirdjo $d k k$. (1984) dan Kusmana (1977), adalah sebagai berikut :

$\mathrm{SDR}=\frac{\text { Kerapatan Nisbi+Frekuensi Nisbi }}{2}$

a. Kerapatan mutlak suatu jenis = Jumlah individu setiap jenis

Kerapatan nisbi suatu jenis $=\frac{\text { Kerapatan mutlak jenis itu }}{\text { Jumlah kerapatan semua jenis }} \times 100 \%$

b. Frekuensi mutlak suatu jenis $=\frac{\text { Jumlah petak contoh berisi jenis itu }}{\text { Jumlah semua petak contoh }}$

c. Frekuensi nisbi suatu jenis $=\frac{\text { Frekuensi mutlak jenis itu }}{\text { Jumlah Frekuensi Mutlak Semua Jenis }} \times 100 \%$

\section{HASIL dan PEMBAHASAN}

Berikut disajikan hasil pengamatan dan analisis statistika uji efektifitas pengendalian gulma secara kimiawi dan manual pada lahan replanting karet perkebunan rakyat dusun Suka damai desa Pondok meja, kecamatan Mestong, kabupaten Muaro Jambi. 
Jurnal Media Pertanian Vol. 1 No. 1 Tahun 2016 Hal. 36 - 44

Media Komunikasi Hasil Penelitian dan Review Literatur Bidang Ilmu Agronomi

ISSN $2503-1279$

\section{Koefisien Komunitas (C) Gulma}

Dari hasil perhitungan koefisien komunitas diperoleh data bahwa petak contoh I dan II memiliki nilai koefisien komunitas (C) lebih dari $75 \%$ pada perbandingan nilai keofisien komunitas (C) berdasar nilai kerapatan mutlak dan kerapatan nisbi sehingga areal replanting karet di lokasi penelitian dapat dilakukan aplikasi pengendalian herbisida.

Tabel 1. Perbandingan Nilai Koefisien Komunitas (C) antar Petak Contoh Berdasarkan Nilai Kerapatan Mutlak

\begin{tabular}{cccc}
\hline Petak & C $(\%)$ & Petak & C (\%) \\
\hline I : II & 92,72 & II : III & 44,95 \\
\hline I : III & 47,87 & II : IV & 65,80 \\
\hline I : IV & 71,90 & III :IV & 68,65 \\
\hline
\end{tabular}

Tabel 2. Perbandingan Nilai Koefisien Komunitas (C) antar Petak Contoh Berdasarkan Nilai Kerapatan Nisbi

\begin{tabular}{cccc}
\hline Petak & C $(\%)$ & Petak & C (\%) \\
\hline I $:$ II & 95,48 & II $:$ III & 60,05 \\
\hline I $:$ III & 60,21 & II : IV & 84,29 \\
\hline I $:$ IV & 86,11 & III $:$ IV & 70,50 \\
\hline
\end{tabular}

Dilihat dari hasil nilai perhitungan koefisien komunitas (C) menunjukkan bahwa nilai $\mathrm{C}>75 \%$, artinya lahan replanting ini memenuhi syarat untuk dapat dijadikan tempat melakukan percobaan pengendalian gulma menggunakan herbisida karena jenis gulma bersifat homogen atau seragam

\section{Dominansi Gulma Sebelum Pengendalian}

Dari hasil identifikasi diketahui ada 15 Jenis gulma yaitu : Melastoma affinae, Cleome rutidospermae, Euphorbia hirta, Axonopus compressus, Centotecha lappacea, Cyperus kylingia, Paspalum conjugatum, Clidemia hirta, Cyperus pilosus, Croton hirtus, Imperata cylindrica, Ageratum conyzoides, Digitaria fuscescens, Mikania micrantha, dan Cyrtococum oxyphillum.

Hasil analisis vegetasi gulma dengan metode kuadrat menunjukkan bahwa jenis gulma yang dominan tumbuh pada areal penelitian yang ditunjukkan oleh nilai SDR disajikan dalam Gambar 1. 
Jurnal Media Pertanian Vol. 1 No. 1 Tahun 2016 Hal. 36 - 44

Media Komunikasi Hasil Penelitian dan Review Literatur Bidang Ilmu Agronomi ISSN $2503-1279$

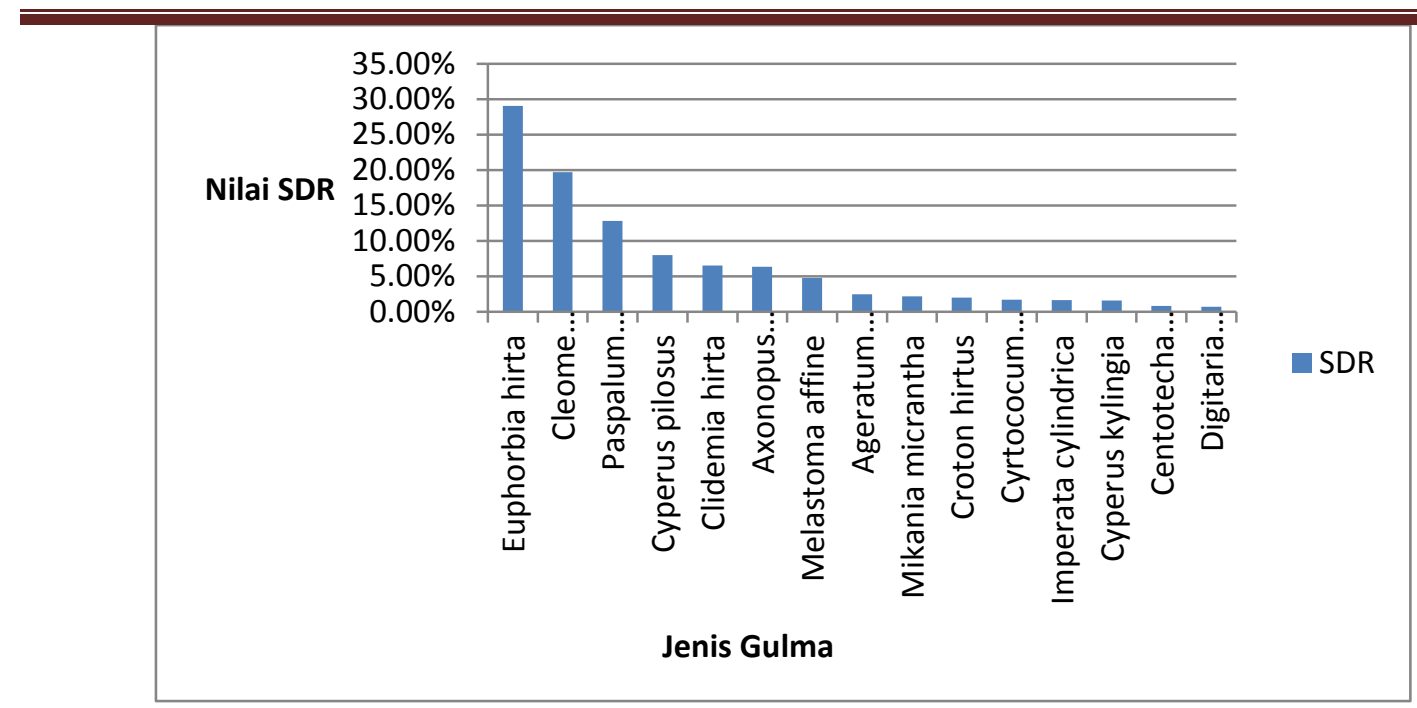

Gambar 1. Nilai SDR Beberapa Jenis Gulma Sebelum Perlakuan Pengendalian

Dari Gambar 1 dapat dijelaskan bahwa spesies gulma yang dominan adalah Euphorbia hirta dengan nilai SDR 29,02\%, hal ini dikarenakan gulma tersebut mampu berbunga sepanjang tahun sehingga reproduksi dan perkembangannya pun berlangsung cepat, menyukai tanah agak lembab, agak toleran dengan suasana ternaung. Selain itu, karena areal penelitian termasuk dataran rendah $(57 \mathrm{~m}$ dpl) sehingga Euphorbia hirta mampu tumbuh dengan baik karena gulma ini hidup dan menyebar pada daerah dengan ketinggian 0-1400 m dpl. Euphorbia hirta termasuk gulma yang kurang penting pada areal perkebunan karet, masalah yang ditimbulkannya tidak berat, namun bersama gulma lain dapat menjadi saingan bagi tanaman karet muda di pembibitan dan areal tanaman belum menghasilkan, mengganggu penanaman penutup tanah kacangkacangan. Pengendalian secara manual cukup efektif seperti dilakukan dengan mencabut ataupun membabat.

Gulma yang memiliki nilai dominansi paling kecil berdasarkan nilai SDR sebelum perlakuan pengendalian yaitu gulma Digitaria puscescens (SDR 0,67\%), gulma yang tergolongan gulma rumput ini kemungkinan sulit berkembangbiak karena benih masih banyak yang mengalami dormansi dan tertutup oleh gulma dominan sehingga kurang mendapat cahaya untuk berkecambah dan berkembang.

\section{Efektifitas Pengendalian Kimia dan Manual}

Persentase gulma yang mati melalui pengendalian manual sebanyak $100 \%$ untuk semua jenis gulma. Gulma yang dikendalikan secara kimia dengan herbisida kontak juga 100\% mati, sedangkan gulma yang dikendalikan dengan herbisida sistemik belum mati sampai pengamatan minggu keempat (hanya 92\%) mati untuk Melastoma affinae, dan gulma lainnya mengalami kematian $100 \%$ 
Jurnal Media Pertanian Vol. 1 No. 1 Tahun 2016 Hal. 36 - 44

Media Komunikasi Hasil Penelitian dan Review Literatur Bidang Ilmu Agronomi ISSN $2503-1279$

Tabel 3. Persentase Gulma Melastoma affinae yang mati setelah Aplikasi Pengendalian Kimia dan Manual

\begin{tabular}{ccccc}
\hline $\begin{array}{c}\text { Perlakuan } \\
\text { Pengendalian } \\
\text { Gulma }\end{array}$ & $\begin{array}{c}\text { Minggu Ke-1 } \\
(\%)\end{array}$ & $\begin{array}{c}\text { Minggu Ke-2 } \\
(\%)\end{array}$ & $\begin{array}{c}\text { Minggu Ke-3 } \\
(\%)\end{array}$ & $\begin{array}{c}\text { Minggu Ke-4 } \\
(\%)\end{array}$ \\
\hline $\begin{array}{c}\text { Herbisida } \\
\text { Paraquat }\end{array}$ & 100 & 100 & 100 & 100 \\
\hline $\begin{array}{c}\text { Herbisida } \\
\text { Glifosat }\end{array}$ & 89 & 92 & 92 & 92 \\
\hline Manual & 100 & 100 & 100 & 100 \\
\hline
\end{tabular}

Dilihat dari nilai yang diperoleh, pengendalian kimia lebih efektif dalam menekan pertumbuhan gulma baru, namun pengendalian manual lebih efektif dalam mematikan gulma karena cara aplikasinya dengan mencabut langsung gulma yang tumbuh Tetapi dalam waktu satu minggu setelah aplikasi, petak perlakuan manual mulai ditumbuhi kembali oleh gulma.

Paraquat adalah nama dagang untuk 1,1-dimethyl-4,4'-bipyridinium dichloride. Herbisida paraquat bekerja dalam kloroplas. Kloroplas merupakan bagian dalam proses fotosintesis, yang mengabsorbsi cahaya matahari yang digunakan untuk menghasilkan gula. Dalam kondisi intensitas cahaya yang tinggi, paraquat akan segera bekerja sebagai herbisida kontak, mematikan semua bagian tanaman yang berwarna hijau. Sedangkan dalam kondisi gelap, paraquat dan diquat akan melakukan penetrasi dalam jaringan daun ke sistem vaskular. Kematian akan terjadi secara lambat dalam kondisi gelap.

Herbisida sistemik yang digunakan dalam penelitian yaitu berbahan aktif glifosat. Glifosat dapat berpengaruh pada pigmen hingga terjadi klorotik, pertumbuhan terhenti dan tanaman mati (Moenandir, 2010). Menurut Sriyani (2008), glifosat sangat efektif mengendalikan gulma rumput dan daun lebar yang mempunyai perakaran dalam dan diaplikasikan sebagai herbisida pasca tumbuh.

\section{Dominansi Gulma Setelah Pengendalian}

Jenis gulma yang tumbuh satu minggu setelah pengendalian secara manual belum dapat teridentifikasi karena gulma dalam masa akan berkecambah. Jenis gulma yang tumbuh dua minggu setelah pengendalian secara manual juga belum dapat diidentifikasi karena ukuran gulma yang kecil sehingga sulit untuk dibandingkan dengan gulma sekitar areal penelitian. Tiga minggu setelah pengendalian secara manual diketahui jenis gulma yang tumbuh yaitu Cleome rutidospermae, Euphorbia hirta dan Croton hirtus. Jenis gulma yang tumbuh empat minggu setelah pengendalian yaitu Cleome rutidospermae, Euphorbia hirta, Melastoma affine dan Croton hirtus. 
Jurnal Media Pertanian Vol. 1 No. 1 Tahun 2016 Hal. 36 - 44

Media Komunikasi Hasil Penelitian dan Review Literatur Bidang Ilmu Agronomi

ISSN $2503-1279$

\begin{tabular}{|c|c|c|c|c|}
\hline \multirow{2}{*}{$\begin{array}{c}\text { Petak } \\
\text { Perlakuan }\end{array}$} & \multicolumn{4}{|c|}{ Waktu Pengamatan } \\
\hline & Minggu 1 & Minggu 2 & Minggu 3 & Minggu 4 \\
\hline P3 I & $\mathrm{Bt}$ & $\mathrm{Bt}$ & $\begin{array}{l}\text { Cleome rutidospermae, } \\
\text { Euphorbia hirta dan } \\
\text { Croton hirtus }\end{array}$ & $\begin{array}{l}\text { Cleome rutidospermae, } \\
\text { Euphorbia hirta dan } \\
\text { Croton hirtus }\end{array}$ \\
\hline P3 II & $\mathrm{Bt}$ & $\mathrm{Bt}$ & $\begin{array}{l}\text { Cleome rutidospermae, } \\
\text { Euphorbia hirta dan } \\
\text { Croton hirtus }\end{array}$ & $\begin{array}{l}\text { Cleome rutidospermae, } \\
\text { Euphorbia hirta, } \\
\text { Melastoma affine dan } \\
\text { Croton hirtus }\end{array}$ \\
\hline P3 III & $\mathrm{Bt}$ & $\mathrm{Bt}$ & $\begin{array}{l}\text { Cleome rutidospermae, } \\
\text { Euphorbia hirta dan } \\
\text { Croton hirtus }\end{array}$ & $\begin{array}{l}\text { Cleome rutidospermae, } \\
\text { Euphorbia hirta dan } \\
\text { Croton hirtus }\end{array}$ \\
\hline P3 IV & $\mathrm{Bt}$ & $\mathrm{Bt}$ & $\begin{array}{l}\text { Euphorbia hirta dan } \\
\text { Croton hirtus }\end{array}$ & $\begin{array}{l}\text { Cleome rutidospermae, } \\
\text { Euphorbia hirta dan } \\
\text { Croton hirtus }\end{array}$ \\
\hline
\end{tabular}

Ket: $\mathrm{Bt}=$ belum teridentifikasi

Pengendalian menggunakan herbisida paraquat dan glifosat mampu menekan pertumbuhan jenis gulma baru sehingga pada pengamatan minggu pertama sampai minggu keempat tidak ada jenis gulma baru yang tumbuh.

Pada pengamatan minggu keempat ditemukan 10 jenis gulma yang masih bertahan atau mampu tumbuh kembali yang berada pada petak pengendalain manual dan petak kontrol. Nilai SDR dari masing-masing jenis gulma dapat disajikan dalam Gambar 2.

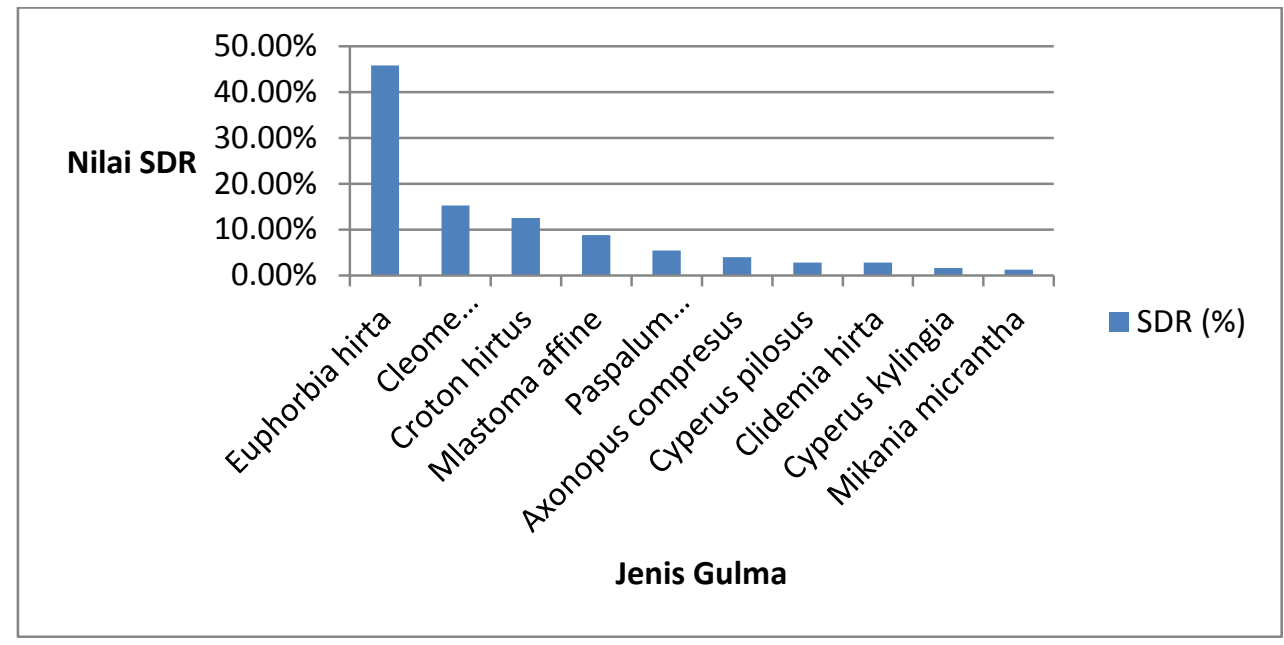

Gambar 2. Nilai SDR Beberapa Jenis Gulma Setelah Perlakuan Pengendalian

Gambar 2 menunjukkan, setelah satu bulan aplikasi perlakuan pengendalian gulma yang memiliki nilai SDR tertinggi yaitu Euphorbia hirta dengan nilai SDR 45,80\%. Dengan membandingkan nilai SDR gulma sebelum aplikasi pengendalian 
Jurnal Media Pertanian Vol. 1 No. 1 Tahun 2016 Hal. 36 - 44

Media Komunikasi Hasil Penelitian dan Review Literatur Bidang Ilmu Agronomi

ISSN $2503-1279$

dengan nilai SDR gulma setelah pengendalian diketahui jenis gulma yang paling dominan setelah aplikasi yaitu ; Euphorbia hirta (SDR 45,80\%), Cleome rutidospermae (SDR 15,26\%), Croton hirtus (SDR 12,52\%), Melastoma affine (SDR 8,82\%), dan Paspalum conjugatum (SDR 5,38\%). Dari hasil perbandingan nilai SDR gulma sebelum dan setelah perlakuan pengendalian diperoleh data bahwa nilai SDR pada gulma dominan Euphorbia hirta mengalami peningkatan dari $29,02 \%$ menjadi $45,80 \%$, gulma Cleome rutidospermae mengalami penurunan nilai SDR dari 19,70\% menjadi $15,26 \%$. Hal ini menunjukkan bahwa terdapat pengaruh pemberian perlakuan terhadap keberadaan dan pertumbuhan gulma pada areal penelitian.

\section{KESIMPULAN}

Dari hasil penelitian dapat disimpulkan bahwa gulma dominan pada areal replanting karet dusun Suka damai desa Pondok meja sebelum perlakuan pengendalian gulma berdasarkan nilai SDR adalah Euphorbia hirta (SDR 29,02\%), Cleome rutidospermae (SDR 19,70\%), Paspalum conjugatum (SDR 12,82\%), Cyperus pilosus (SDR 7,99\%), dan Clidemia hirta (SDR 6,49\%). Perlakuan pengendalian gulma secara kimiawi dengan herbisida paraquat dan herbisida glifosat lebih efektif dalam menekan pertumbuhan gulma baru dibandingkan dengan perlakuan pengendalian gulma secara manual. Terdapat perbedaan nilai SDR setelah perlakuan pengendalian gulma secara kimiawi dan manual yaitu pada gulma yang paling dominan Euphorbia hirta mengalami peningkatan dari $29,02 \%$ menjadi 45,80\%, gulma Cleome rutidospermae mengalami penurunan nilai SDR dari $19,70 \%$ menjadi $15,26 \%$.

\section{DAFTAR PUSTAKA}

Anwar R. 2007. Uji Berbagai Herbisida Dalam Pengendalian Gulma Tanaman Karet. Publikasi. Skripsi. Fakultas Pertanian. Universitas Prof, Dr. Hazairin. Bengkulu. http://risvananwar.wordpress.com

Barus E. 2003. Pengendalian Gulma di Perkebunan. Kanisius. Yogyakarta.

BPS. 2012. Kecamatan Mestong Dalam Angka Tahun 2012. Badan Pusat Statistik Kabupaten Muaro Jambi. Jambi.

Henry. 2010. Pengendalian Gulma secara Kimiawi. IPB. Bogor. http://iirc.ipb.ac.id Kusmana, C. 1997. Metode Survey Vegetasi. Institut Pertanian Bogor. Bogor. Lubis, A.U. 1992. Kelapa Sawit (Elaeis quineensis Jacq.) Di Indonesia. Pusat

Penelitian Perkebunan Marihat-Bandar Kuala, Pematang Siantar. SumateraUtara.

Mangoensoekarjo, S. 1983. Gulma dan Cara Pengendalian pada Budidaya Perkebunan.Ditlintanbun, Dirjen Perkebunan, Departemen Pertanian.

Nurjanah, U. 2002. Pergeseran Gulma dan Hasil Jagung Manis pada Tanpa Olah Tanah Akibat Dosis dan Waktu Pemberian Glyphosat. Publikasi. Fakultas Pertanian. Universitas Bengkulu. Bengkulu. http://www.bdpunib.org

Purba, E. 2000. Pengujian Lapangan Efikasi Herbisida Ristop 240 AS Terhadap Gulma Pada Budidaya Karet Menghasilkan. Publikasi. Program Studi Agronomi. Fakultas Pertanian. Universitas Sumatera Utara. http://www.library.ac.id 
Jurnal Media Pertanian Vol. 1 No. 1 Tahun 2016 Hal. 36 - 44

Media Komunikasi Hasil Penelitian dan Review Literatur Bidang Ilmu Agronomi ISSN $2503-1279$

Tjitrosoedirdjo S., Utomo I.H., Wiroatmodjo J. 1984. Pengelolaan Gulma di Perkebunan. PT. Gramedia. Jakarta.

Wahyudi, Panggabean T.R., Pujiyanto. 2008. Panduan Budidaya Tanaman Karet. Penebar Swadaya. Jakarta.

Yarnelis dan Yakup. 1991. Gulma dan Teknik Pengendaliannya. PT. Raja Grafindo Persada. Jakarta. 